\title{
HIV-1 Envelope Glycoprotein Trafficking and Viral Transmission ${ }^{+}$
}

\author{
Melissa Victoria Fernandez 1, Lwar N Naing ${ }^{1}$, David A Scheiblin ${ }^{2}$, Sherimay D Ablan ${ }^{\text {, }}$ \\ Jennifer A Simmons ${ }^{1}$ and Eric $O$ Freed ${ }^{1, *}$ \\ 1 HIV Dynamics and Replication Program, Center for Cancer Research, National Cancer Institute, \\ Frederick, MD 21702, USA; melissa.fernandez2@nih.gov (M.V.F.); lwar.naing@nih.gov (L.N.N.); \\ sablan@mail.nih.gov (S.D.A.); Jennifer.simmons@geneva.edu (J.A.S.) \\ 2 Optical Microscopy and Analysis Laboratory, Cancer Research Technology Program, Frederick National \\ Laboratory for Cancer Research, Frederick, MD 21702, USA; david.scheiblin@nih.gov \\ * Correspondence: efreed@mail.nih.gov \\ † Presented at Viruses 2020-Novel Concepts in Virology, Barcelona, Spain, 5-7 February 2020. \\ Published: 4 June 2020
}

\begin{abstract}
HIV-1 encodes an envelope glycoprotein complex (Env) containing a long cytoplasmic tail (CT) harboring trafficking motifs implicated in Env incorporation into virions. Although the requirement for the Env $\mathrm{CT}$ in viral transmission is known, the precise mechanism by which Env is incorporated into nascent virions and localizes to the virological synapse remains poorly defined. To further elucidate the mechanism of Env trafficking, we examined three HIV-1 strains: the labadapted clade B strain, NL4-3, and a transmitted/founder (T/F) clade C virus, K3016, and a T/F clade $\mathrm{B}$ virus, $\mathrm{CH} 077$. The HIV-1 Env CT contains two invariant trafficking motifs: tyrosine endocytosis motif, $\mathrm{Y}^{712} \mathrm{SPL}$, and C-terminal dileucine motif, LL ${ }^{855}$. Virion Env incorporation analysis revealed that Y712SPL is necessary for efficient Env incorporation, while LL ${ }^{855}$ is dispensable. Spreading infection kinetics were analyzed in various T-cell lines and primary human PBMCs; the results indicated that both endocytic motifs contribute to efficient viral spread in culture. Analysis of Env localization to the T-cell uropod, the portion of the plasma membrane that forms a virological synapse with uninfected cells, was found to be dependent on the Env CT and the Y712SPL motif. Cell-to-cell and cell-free transmission assays using $\mathrm{T}$ cells infected with HIV-1 bearing $\mathrm{Y}_{712} \mathrm{~A}$ or LL855AA Env CT mutations are ongoing to establish a role for these motifs in both modes of viral transmission. These studies will significantly enhance our understanding of Env trafficking and viral transmission, providing insights into viral Env-host interactions in physiologically relevant cells.
\end{abstract}

Keywords: HIV-1; Env; gp41; cytoplasmic tail; transmission; endocytosis; virological synapse

(C) 2020 by the authors. Licensee MDPI, Basel, Switzerland. This article is an open access article distributed under the terms and conditions of the Creative Commons Attribution (CC BY) license (http://creativecommons.org/licenses/by/4.0/). 